\title{
A study on cyber sickness reduction by oculo-motor exercise performed immediately prior to viewing virtual reality (VR) content on head mounted display (HMD)
}

\author{
Won Deok Park', Seong Wook Jang ${ }^{2}$, Yeol Ho Kim ${ }^{3}$, Gyu Ah Kim', Wookho Son ${ }^{4}$, \\ Yoon Sang Kim ${ }^{6}$ \\ ${ }^{1,4,}$ Institute for Bioengineering Application Technology, Korea University of Technology and Education, \\ Cheonan, Republic of Korea \\ ${ }^{2,3,6}$ Department of Computer Science and Engineering, Korea University of Technology and Education, \\ Cheonan, Republic of Korea \\ ${ }^{5}$ Electronics and Telecommunications Research Institute (ETRI), Daejeon, Republic of Korea \\ ${ }^{6}$ Corresponding author \\ E-mail: ${ }^{1} p w d 317 @ k o r e a t e c h . a c . k r,{ }^{2} e l d e r l o r d @ k o r e a t e c h . a c . k r,{ }^{3} k i m y h o 93 @ k o r e a t e c h . a c . k r$, \\ ${ }^{4} k g a 1203 k r @ n a v e r . c o m, 5$ whson@etri.re.kr, 6 yoonsang@koreatech.ac.kr
}

Received 19 September 2017; accepted 29 September 2017

DOI https://doi.org/10.21595/vp.2017.19170

Abstract. The purpose of this study was to investigate the effect of performing an oculo-motor exercise, immediately prior to watching VR (virtual reality) content on HMD (head mounted display), on cyber sickness. Eight subjects participated in a test. The results were analyzed based on three categories of symptoms associated with cyber sickness (nausea, disorientation, oculomotor) to assess the effect of oculo-motor exercise on cyber sickness. Additionally, the Simulator Sickness Questionnaire (SSQ) test was used as a parameter for the evaluation. The proposed method resulted in a significant reduction in cyber sickness $(p<0.01)$ in all the three groups. Therefore, the proposed method was effective in alleviating cyber sickness.

Keywords: cyber sickness, head mounted display, oculo-motor exercises, simulator sickness questionnaire, virtual reality.

\section{Introduction}

In general, visual symptoms such as pain, discomfort, and fatigue are exhibited when one views VR content on HMD. An image viewed in reality and an image viewed on a VR setup on HMD differ because of vergence-accommodation conflict [1]. Symptoms of visual fatigue include eye fatigue, tears, ocular pressure, pain around the eyes, discomfort when blinking eyes, difficulty in focusing, and blurred vision. This can cause headaches, dizziness, and vomiting.

Several studies have aimed to alleviate cyber sickness [2-4]. However, no study has explored the role of oculo-motor exercises in alleviating cyber sickness. So far, oculo-motor exercises have demonstrated their effectiveness in the fields of medicine and sports. In particular, studies have reported that oculo-motor exercises improve vision, reduce strain on eyes, and are beneficial against myopia $[5,6]$. In addition, studies have also shown that oculo-motor exercises are effective in maintaining vision and posture in cerebral palsy disease [7].

Therefore, oculo-motor exercises may have beneficial effects against cyber sickness. In this study, we investigated the effect of oculo-motor exercise on cyber sickness by performing such exercises immediately prior to viewing VR content on HMD.

\section{Materials and methods}

\subsection{Subjects}

Eight subjects participated in this study (both males and females). The subjects were not colorblind and had no history of epilepsy. The subjects were not exposed to virtual reality until 30 days before the experiment. The subjects had a corrected visual acuity of 0.5-1.0. All subjects were 
fully informed about the method, procedure, and purpose of the experiment and voluntarily participated in the study. Cyber sickness was experimented with one group due to individual differences (Table 1).

Table 1. Detailed information regarding subjects

\begin{tabular}{|c|c|c|c|c|c|c|}
\hline & \multicolumn{2}{|c|}{ Gender } & Age & Vision & \multirow{2}{*}{ Medical history } & \multirow{2}{*}{ Grand total } \\
\cline { 2 - 5 } & Males & Females & 20 's & $0.5-1.0$ & & 8 \\
\hline Number of individuals & 5 & 3 & 8 & 8 & 0 & 8 \\
\hline
\end{tabular}

\subsection{Experimental design}

The experiment was conducted from 10:00 AM to 11:00 AM. One hour before beginning the experiment, the subjects were informed of precautions needed for oculo-motor exercises and viewing VR content. The experiment was conducted in an isolated area and was designed to minimize the influence of surroundings.

Samsung's gear VR (SM-R323) HMD (head mounted display) was used for viewing VR images, and Samsung Galaxy S7 model (SM-G935K) was used for conducting the test. The VR images were presented using Samsung's VR application (The batman VR experience). Subjects were allowed to view VR content for 5 minutes, as it has been reported that more than $80 \%$ of VR users experienced cyber disturbance within 10 minutes [8].

The oculo-motor exercises were performed for 5 minutes. These exercises were performed stepwise with the help of a guide.

The Simulator Sickness Questionnaire (SSQ) was used to measure cyber sickness. The first SSQ was answered 10 minutes before and the second SSQ was answered after the experiment (viewing a VR content on HMD). The third SSQ was answered on the next day, after performing oculo-motor exercises and viewing a VR content on HMD.

\subsection{Measurement of responses}

Cyber sickness was measured using the traditional method of SSQ [9]. Experiences were recorded on a 4-point scale (0; no sickness, 1; mild sickness, 2; considerable sickness, 3; severe sickness) to assess the cyber sickness of subjects. These numerical values were used to calculate the mean value and the standard deviation of subjects' responses to each question. The overall score was obtained by calculating the corrections for items 14 to 16, and then applying the same to the total sum. Cyber sickness was assessed by the total score and the subjects were divided into three groups according to the symptoms (nausea, oculo-motor, and disorientation; The score for each symptom group was $\mathrm{M}=[1] \times 9.45, \mathrm{O}=[2] \times 7.58$, and $\mathrm{D}=[3] \times 13.92$. We applied specific weighting factors to each group. The overall score was calculated by multiplying the values of [1-3] by a specific coefficient of 3.75, according to the symptom [10].

The difference between the mean values obtained before and after experiment was analyzed by using $t$-test. SPSS 18 [11] was used for statistical analysis. Statistical significance was considered at $p<0.05$ and $p<0.01$ (Table 2).

\subsection{Oculo-motor exercises}

The exercise paradigm used in this study includes oculo-motor exercises and gaze stability exercise [12-14]. The paradigm consists of four steps: range oculo-motor exercises, saccadic oculo-motor exercises, pursuit oculo-motor exercises, and vergence oculo-motor exercises (Table 3). 
Table 2. Assessment of responses to simulator sickness questionnaire [9]

\begin{tabular}{|c|c|c|c|}
\hline Symptom $(0,1,2,3)$ & Nausea $(\mathrm{N})$ & Oculomotor $(\mathrm{O})$ & Disorientation (D) \\
\hline General discomfort & 1 & 1 & \\
\hline Fatigue & & 1 & \\
\hline Eye fatigue & & 1 & \\
\hline Difficulty in focusing eyes & & 1 & \\
\hline Increased salivation & & 1 & 1 \\
\hline Perspiration & 1 & & \\
\hline Nausea-related & 1 & & \\
\hline Difficult to concentrate & 1 & & 1 \\
\hline Feeling full of head & 1 & 1 & \\
\hline Blurred vision & & & 1 \\
\hline Dizziness on opening eyes & & & 1 \\
\hline Dizziness on closing eyes & & & 1 \\
\hline Dizziness & & & 1 \\
\hline Burden of camouflage & & & 1 \\
\hline Burp & 1 & & \\
\hline Sum & {$[1]$} & [2] & {$[3]$} \\
\hline \multirow{2}{*}{ Calculation method } & $\mathrm{N}=[1] \times 9.54$ & $\mathrm{O}=[2] \times 7.58$ & $\mathrm{D}=[3] \times 13.92$ \\
\hline & \multicolumn{3}{|c|}{ Overall score $=([1]+[2]+[3]) \times 3.74$} \\
\hline
\end{tabular}

Table 3. Oculo-motor exercise paradigm

\begin{tabular}{|c|c|c|c|}
\hline Exercise order & Procedure & $\begin{array}{l}\text { Exercise } \\
\text { Duration } \\
\end{array}$ & $\begin{array}{c}\text { Exercise } \\
\text { order }\end{array}$ \\
\hline $\begin{array}{l}\text { 1. Range oculo-motor } \\
\text { exercise }\end{array}$ & $\begin{array}{l}\text { 1) Close your eyes. } \\
\text { 2) Slowly left-right, up-down, diagonal, and } \\
\text { rotate your eyes. }\end{array}$ & 75 & \\
\hline $\begin{array}{c}\text { 2. Saccadic } \\
\text { oculo-motor exercise }\end{array}$ & The eyes are fixated on newly appearing objects. & 75 & \\
\hline $\begin{array}{c}\text { 3. Pursuit } \\
\text { oculo-motor exercise }\end{array}$ & $\begin{array}{l}\text { Keep your eyes fixated on slowly moving } \\
\text { objects. }\end{array}$ & 75 & 5 \\
\hline $\begin{array}{l}\text { 4. Vergence } \\
\text { oculo-motor exercises }\end{array}$ & $\begin{array}{l}\text { 1) Move your eyes slowly from the nearest point } \\
\text { to a point far away (about } 5 \mathrm{~cm} \rightarrow \text { about } 50 \mathrm{~cm} \text { ). } \\
\text { 2) Move your eyes slowly from a point far away } \\
\text { to a point nearby (about } 50 \mathrm{~cm} \rightarrow \text { about } 5 \mathrm{~cm} \text { ). }\end{array}$ & 75 & \\
\hline
\end{tabular}

\section{Results}

Table 4 shows the effect of oculo-motor exercises on cyber sickness, as indicated by SSQ scores and subsequent t-test results (Fig. 1).

The initial score of nausea-related cyber sickness was 65.59. After performing oculo-motor exercises, the score was 10.73. The difference between the scores obtained before and after oculo-motor exercises was significantly lower $(-54.86)(p<0.01)$. The score of oculomotor-related cyber sickness was 69.17 initially. After performing oculo-motor exercises, the score was 16.11. The difference between the scores obtained before and after oculo-motor exercises was significantly lower $(-53.06)(p<0.01)$. The score of disorientation-related cyber sickness was 144.42 initially. The score after performing oculo-motor exercises was 34.80 . The difference between the scores obtained before and after exercises was significantly lower $(-109.62)(p<0.01)$.

The differences in the scores mentioned above indicate that disorientation-related, nausea-related, and oculomotor-related cyber sickness was alleviated to a considerable extent. 
Table 4. Analysis of cyber sickness before and after oculo-motor exercises $(N=8)$

\begin{tabular}{|c|c|c|c|c|c|c|c|}
\hline \multirow{2}{*}{$\begin{array}{c}\text { Symptoms of } \\
\text { cyber sickness }\end{array}$} & $\begin{array}{c}\text { Before viewing } \\
\text { VR content }\end{array}$ & \multicolumn{2}{|c|}{$\begin{array}{c}\text { After viewing VR content } \\
\text { (oculo-motor exercises } \times \text { ) }\end{array}$} & $\begin{array}{c}\text { After viewing VR content } \\
\text { (oculo-motor exercises } \circ \text { ) }\end{array}$ & \\
\cline { 2 - 8 } & SSQ & $\mathrm{M}$ & SSQ & M & SSQ & M & $\mathrm{t}$ \\
\hline Nausea (N) & 4.77 & 4.77 & 65.59 & 65.59 & 10.73 & 10.73 & $3.781^{* *}$ \\
\hline $\begin{array}{c}\text { Dis orientation } \\
(\mathrm{D})\end{array}$ & 15.16 & 15.16 & 69.17 & 69.17 & 16.10 & 16.11 & $4.864^{* *}$ \\
\hline
\end{tabular}

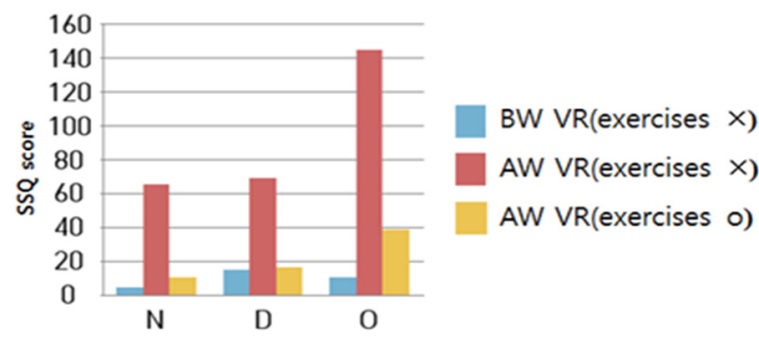

Fig. 1. Analysis of cyber sickness (N, D, O) before and after oculo-motor exercises.

* N: Nausea-related, D: Disorientation-related, O: Oculomotor-related

* BW VR: Before viewing VR content, AR VR: After viewing VR content

\section{Conclusions}

To analyze the effect of the proposed oculo-motor exercises on cyber sickness, SSQ questionnaire and $t$-test statistical methods were used.

The results indicate that the proposed oculo-motor exercises are an effective approach to alleviate cyber sickness. In addition, the analysis of the results from the different groups based on symptoms revealed differences in the effect of oculo-motor exercises for each group.

In fact, it is clear that visual disturbance and fatigue caused by viewing VR content are due to vergence-accommodation conflict. Vergence-accommodation conflict causes visual fatigue as the brain must utilize considerable resources to correct this mismatch [14].

The oculo-motor exercises have been found to have a beneficial effect on visual acuity, eye tension, myopia, cerebral palsy, visual perception, and maintenance of upright posture [5-7]. Therefore, oculo-motor exercises immediately prior to viewing VR content on HMD appear to have a beneficial effect on ocular muscle and cranial nerve function [15]. Further, the oculo-motor exercises performed immediately before viewing a VR content on HMD would have affected the alignment of the object image on the fovea centralis when the subject moved, and consequently, the ability to maintain the object in focus [16].

Taken together, the results indicate that the proposed method (that is, performing oculo-motor exercises immediately before viewing a VR content on HMD) is an effective way to alleviate cyber sickness.

\section{Acknowledgement}

This work was supported by Institute for Information and Communications Technology Promotion (IITP) Grant funded by the Korea Government (MSIT) (No. 2017-0-00289-001).

\section{References}

[1] Hoffman D. M., Girschick A. R., Akeley K., Banks. M. S. Vergence-accommodation conflicts hinder visual performance and cause visual fatigue. Journal of Vision, Vol. 8, 2008, p. 1-30. 
[2] Kennedy R. S., Stanney K. M., Dunlap W. P. Duration and exposure to virtual environments: sickness curves during and across sessions. Presence: Teleoperators and Virtual Environments, Vol. 9, 2000, p. 463-472.

[3] Seay A. F., Krum D. M., Hodges L., Ribarsky. W. Simulator sickness and presence in a high FOV virtual environment. Proceedings IEEE Virtual Reality, 2001, p. 299-300.

[4] Arshad Q., Cerchiai N., Goga U., Nigmatullina Y., Ed Roberts R., Augusto P., Casani, John F. Golding, Michael A. Gresty, Adolfo M. Bronstein. Electrocortical for motion sickness. The Official Journal of the American Academy of Neurology, Vol. 6, 2015, p. 1257-1259.

[5] Bates W. H. The Bates Method for Better Eyesight Without Glasses. Henry Holt, 1943.

[6] Rosanes B., Marilyn B. Scoop! Eye Doctor Eye Movement: Making Without Surgery, That Visual Acuity of Dream 1.2. Chaekgwagis, Seoul, 2013.

[7] Im Ae-Jin The effect of Eye Movement Program on postural control and visual perceptual ability of children with spastic cerebral palsy. Journal of Korean Society of Occupational Therapy, Vol. 19, 2011, p. 85-96.

[8] Cobb S. V., Nichols S., Ramsey A., Wilson. J. R. Virtual reality-induced symptoms and effects (VRISE). Presence, Vol. 8, 1999, p. 169-186.

[9] Kennedy R. S., Lane N. E. Simulator sickness questionnaire. Aviation Psychology, Vol. 3, 1993, p. 203-220.

[10] Lee C. M., Jung J. H. The study on using effect of head mounted display to the body in virtual environments. Korea Multimedia Society, Vol. 3, 2000, p. 389-398.

[11] Won T., Jung S. SPSS PASW Statistics 18.0 Statistical Research Analysis. Hannarae Academy, 2010, p. 427-432.

[12] Hain T. C., Helminski J. O. Evaluation and Treatment of Benign Paroxysmal Positional Vertigo. FA Davis Company, Philadelphia, 2007, p. 2-18.

[13] Cooksey F. S. Rehabilitation in vestibular injury. Proceedings of the Royal Society of Medicine, Vol. 39, Issue 5, 1946, p. 273-278.

[14] Cawthorne T. The physiological basis for exercises. The Chartered Society of Physiotherapy, Vol. 3, 1944, p. 106-107.

[15] Kim J. I. Eye movement in the brain stem. Journal of the Korean Society for Clinical Neurophysiology, Vol. 3, Issue 1, 2001, p. 71-75.

[16] Kim J. S. Physiology of eye movements. Journal of the Korean Society for Clinical Neurophysiology, Vol. 3, Issue 2, 1999, p. 173-181. 